\title{
Editorial
}

\section{Fructose and the Dietary Therapy of Diabetes Mellitus}

\author{
L. Sestoft \\ Hvidøre Hospital, Klampenborg, Denmark
}

The use of fructose in the dietary treatment of diabetes has a very long history [1], but it remains unsolved whether fructose has any place in the dietary treatment of insulin-dependent diabetics today. The saccharine and cyclamate ban in U.S.A. has provoked a renewed interest in the use of fructose as a sweetener for diabetics [2, 3], but still doubt and hesitation prevail. The dietary treatment of insulindependent diabetics is based on a daily supply of significant amounts of slowly absorbed carbohydrates (starch) in a meal pattern, which is repeated from day to day in order to diminish the tendency to hyperglycaemia and or hypoglycaemia between meals. The putative place of fructose in such a dietary scheme should be as a sweetener, i. e. as a substitute for sucrose, not for starch. Because fructose as a sweetener has to be taken in approximately the same amounts as sucrose one problcm has been whether fructose causes a smaller rise in blood glucose concentration than sucrose. Such a beneficial effect of fructose has certainly been found [4].

So why do we not recommend fructose? Fructose is very rapidly metabolized in the liver to glucose and lactate in a way which is independent of insulin [5]. Even in the starved state fructose may turn the liver from a lactate clearing organ to a lactate producing organ. The proportion of fructose which is converted to lactate in the liver is greatly increased by anoxia and a concomitant high glucose concentration (Table 1). Thus fructose metabolism may induce lactate acidosis when there is already insufficient hepatic clearance of peripherally produced lactate. Such an effect has been shown in humans after intravenous administration of fructose and several warnings against this fructose effect have been given in the past 10 years [7, 8, 9]. In fructose infusion studies the arterial concentration of fructose has been about $5 \mathrm{mmol} / 1[10,11,12]$. The effect of fructose on liver metabolism is linearly dependent on the fructose concentration in the low concentration range [13], because of a relatively low affinity for transport across the plasma membrane [14]. Therefore the fructose effects after peroral intake must be anticipated to be strongly dependent on the portal fructose concentration, which has not been measured in humans. However, the following calculation can illustrate what happens after a significant peroral intake of fructose in humans.

If $60 \mathrm{~g}$ of fructose $(330 \mathrm{mmol})$ are taken perorally within a short time (e.g. $10 \mathrm{~min}$ ), absorption will be complete in about $100 \mathrm{~min}$. Because fructose in humans seems to be absorbed and delivered intact to the portal circulation [15] the average fructose concentration in the absorption period will be about $3.3 \mathrm{mmol} / 1$, provided the portal flow is $1000 \mathrm{ml} / \mathrm{min}$. If the liver weight is $1500 \mathrm{~g}$ the average rate of fructose conversion should be $2.2 \mu \mathrm{mol} / \mathrm{min}$ per g liver, provided no fructose passes completely through the liver. The hepatic extraction of fructose is indeed high $[11,12]$ in that there are very low $(0.2 \mathrm{mmol} / 1)$ peripheral fructose concentrations after peroral fructose intake [16]. Thus the average rate of fructose uptake in liver can be estimated to be about $1.75 \mu \mathrm{mol} / \mathrm{min}$ per $\mathrm{g}$ liver. This relationship between concentration and splanchnic hepatic fructose uptake has been confirmed in fructose infusion experiments [11]. Further, it has been shown that $30 \mathrm{~g}$ fructose given perorally, increases the rate of ethanol oxidation by about $50 \%$ [17]. From this observation two conclusions can be drawn: first, that the major part of fructose given perorally must be metabolized in the same organ as ethanol, namely in the liver, and second, that the rate of fructose conversion to glucose and lactate must be about $1.7 \mu \mathrm{mol} / \mathrm{min} / \mathrm{g}$ liver since in human fructose infusion experiments and pig liver perfusion experiments this rate of fructose metabolism increases the rate of ethanol oxidation by $50-80 \%[11,18]$. Thus it can be concluded that the rate of fructose metabolism in liver is of the same order of magnitude after peroral intake and after infusion of about $1 \mathrm{~g}$ fructose $/ \mathrm{kg} / \mathrm{h}$.

Such a rate of fructose metabolism elicits signifi- 
Table 1. Influence of glucose on the rate of glucose and lactate release from livers of fed rats perfused with a medium containing $10 \mathrm{mmol} / 1$ fructose [6]. The figures show that addition of glucose to a fructose metabolizing liver increases the rate of lactate production by the liver and that with increasing glucose concentration the rate of release of glucose decreases. This is due to an increased rate of glycogen uptake from fructose and glucose. No insulin was added. Negative value denotes uptake. Mean values \pm SEM $(\mathrm{n}=3)$

\begin{tabular}{llll}
\hline Medium & & $\begin{array}{l}\text { Rate of } \\
\text { glucose release }\end{array}$ & $\begin{array}{l}\text { Rate of } \\
\text { lactate release }\end{array}$ \\
\hline $\begin{array}{l}\text { Glucose } \\
\mathrm{mmol} / \mathrm{l}\end{array}$ & $\begin{array}{l}\text { Fructose } \\
\mathrm{mmol} / \mathrm{l}\end{array}$ & \multicolumn{2}{c}{$\begin{array}{l}\text { umol } / \mathrm{min} \text { per g liver }\end{array}$}
\end{tabular}

\begin{tabular}{rrrr}
\hline 0 & 0 & $0.96 \pm 0.16$ & $0.61 \pm 0.28$ \\
0 & 10 & $2.66 \pm 0.19$ & $1.97 \pm 0.15$ \\
5 & 10 & $1.62 \pm 0.14$ & $2.50 \pm 0.19$ \\
10 & 10 & $0.74 \pm 0.43$ & $2.81 \pm 0.33$ \\
25 & 10 & $-0.41 \pm 0.36$ & $2.82 \pm 0.21$ \\
\hline
\end{tabular}

cant disturbances in the metabolism of perfused livers from rats. For instance, in perfused rat liver the concentration of energy rich phosphates, in particular ATP, is decreased by about $50 \%$ [14], and in a $10-15 \mathrm{~min}$ period following initiation of fructose metabolism the concentration of inorganic phosphate in the extra mitochondrial compartment decreases to very low values [19]. The concentration of inorganic phosphate decreases to very low values because of accumulation of fructose 1-phosphate in concentrations which are at least 10 times higher than the concentration of other phosphorylated intermediates $[20,21]$. The metabolic consequences of fructose metabolism thus are: a nearly quantitative interconversion of fructose to glucose + lactate, which goes on very rapidly, and which is accompanied by an increase in the intracellular concentration of fructose 1-phosphate and by a decrease in inorganic phosphate concentration. This leaves the liver in a disturbed metabolic state, distinguished by a decrease in the content of ATP, a decreased concentration of total adenine nucleotides, a decrease in the ability of the liver to take up lactate, and with a series of changes in enzymatic regulation (see e.g. [6]). The increased rate of degradation of adenine nucleotides is reflected in a stocheoimetrical increase in the rate of uric acid (or allantoin) formation [22, 23].

For the diabetic the effect of fructose on blood glucose, uric acid production, triglyceride synthesis and ketogenesis are of major importance. The fate of carbon from fructose ingested perorally has not yet been quantitatively investigated. However, in experiments with liver catheterization $[11,12]$ or with ${ }^{14} \mathrm{C}$ labelled fructose [24] in humans given fructose intravenously it appears that only a few percent of fructose is directly oxidized by the liver to $\mathrm{CO}_{2}$ and water, and about $30 \%$ is accounted for by glucose measured in the blood. However, at the same time the rate of net glucose production by the liver is decreased or only slightly increased $[12,24]$, in rare cases leading to overt hypoglycaemia [25], due to accumulation of glycogen in liver [26, 27]. The biochemical mechanism by which fructose induces a large net rate of glycogen formation is well elucidated and is based upon an inhibition of phosphorylase a by the high fructose 1-phosphate concentration, by the very low concentration of $P_{i}$, concomitant with a decreased rate of cyclic AMP production the magnitude of which depend on the level of ATP in the liver tissue [28]. Since the low $P_{i}$ concentration, the high fructose 1-phosphate concentration, and the decrease in ATP, are all involved in the mechanisms of the untoward effects of fructose, the proof of the existence of untoward effects of fructose given perorally may be found in the explanation of its beneficial effect on blood glucose.

Fructose does not inhibit the rate of nonesterified fatty acid (NEFA) uptake in liver or increase its oxidation to $\mathrm{CO}_{2}$ and water significantly, but rapidly decreases the rate of ketone body formation to very low values, and thus the bulk of NEFA taken up must be converted into triglyceride [29]. Such an effect has evidence in the clinical literature [see 30], but conflicting results have been published since a decreased rate of lipolysis in adipose tissue may result in a lowering effect of fructose on plasma triglyceride in normal persons. In the poorly regulated diabetic, the lack of insulin may lead to an exaggaration of the fructose induced rise in plasma triglyceride concentration, but as a whole, we do not know very much about the effects of fructose on blood glucose and triglyceride concentrations in diabetics in different states of regulation. It is reasonable to imagine that when insulin is lacking fructose metabolism will give rise to an increased rate of production of plasma glucose and triglyceride as compared to conditions with normo- or hyperinsulinaemia [31]. On the other hand if a diabetic takes a long-drink containing fructose in order to cope with hypoglycaemic symptoms this may well elicit even more severe hypoglycaemic episodes. This is because fructose does not give rise to any significant increase in blood glucose concentration and partially blocks the ability of the patient to provide glucose from liver glycogen under conditions with hyperinsulinaemia.

It is not easy to accept that the antiketogenic action of fructose [32] should be beneficial for the diabetic. Under conditions with proper insulin treatment, and starvation ketosis, any carbohydrate (also slowly absorbed carbohydrates) will counteract the tendency to ketosis. Under conditions with deficient insulin treatment, fructose administration will cause a decrease in the conversion of NEFA to ketone bodies, and a concomitant decrease in the conversion of lactate to glucose. Thus, the rate of net acid production by the liver may well be increased due to the 
net production of lactate from fructose and the glucose production will continue with fructose as the carbon source. The net outcome will be continued hyperglycaemia, hyperlactataemia and increased triglyceride synthesis.

We do not know anything about the effects of an increased turnover of adenine nucleotides in patients over longer periods, but it seems unreasonable to increase the rate of uric acid production in patients with decreased renal function, e.g., with diabetic nephropathy.

In genetically selected rats fructose, in contrast to starch, leads to the development of diabetes including diffuse glomerulosclerosis [33]. The finding that fructose induces a reduction in insulin-binding affinity to monocytes and a decrease in insulin sensitivity in healthy humans [34] may prove significant for the pathogenic action of sugar in diabetes.

Thus, because many questions, especially on the quantitative aspects of fructose metabolism in relation to the state of regulation in diabetics and on its role in the pathogenesis of diabetes remain unanswered it should be considered wise not to promote the use of fructose as a sweetener for diabetics on a large scale.

\section{References}

1. Külz, E.: Beiträge zur Pathologie und Therapie des Diabetes Mellitus, p. 130. Marburg, 1874

2. Brunzell, J.D.: Use of fructose, xylitol, or sorbitol as sweetener in diabetes mellitus. Diabetes Care 1, 223-230 (1978)

3. Koivisto, V. A.: Fructose as a dietary sweetener in diabetes mellitus. Diabetes Care 1, 241-246 (1978)

4. Arvidsson-Lenner, R.: Specially designed sweeteners and food for diabetics - a real need? Am. J. Clin. Nutr. 29, 726-733 (1976)

5. Davidson, J. N., Kermack, N. O., Mowat, D. M., Stewart, C. P.: Fructose metabolism in the intact animal. Biochem. Z. 30, 433-441 (1936)

6. Sestoft, L.: Control of fructose metabolism in the perfused liver. Thesis. Odense: University Press 1975

7. Sestoft, L.: Fructose - a warning. Ugeskr. Læger, 134, 571 (1972)

8. Woods, H. F., Alberti, K. G. M. M.: Dangers of intravenous fructose. Lancet 1972 II, 1354-1357

9. Van den Berghe, G., Hers, H. G.: Dangers of intravenous fructose and sorbitol. Acta Paediatr. Belg. 31, 115-123 (1978)

10. Miller, M., Drucker, W. R., Owens, J. E., Craig, J. W., Woodward, H.: Metabolism of intravenous fructose and glucose in normal and diabetic subjects. J. Clin. Invest. 31, 115-125 (1952)

11. Tygstrup, N., Winkler, K., Lundquist, F.: The mechanism of the fructose effect on the ethanol metabolism of the human liver. J. Clin. Invest. 44, 817-830 (1965)

12. Bergström, J., Hultman, E.: Synthesis of muscle glycogen in man after glucose and fructose infusion. Acta Med. Scand. 182, 93-107 (1967)

13. Sestoft, L., Tønnesen, K., Hansen, F. V., Damgaard, S. E.: Fructose and D-glyceraldehyde metabolism in the isolated perfused pig liver. Eur. J. Biochem. 30, 542-552 (1972)
14. Sestoft, L., Fleron, P.: Determination of the kinetic constants of fructose transport and phosphorylation in perfused rat liver. Biochim. Biophys. Acta 345, 27-38 (1974)

15. Cook, G. C.: Absorption products of $\mathrm{D}(-)$ fructose in man Clin. Sci. Mol. Med. 37, 675-687 (1969)

16. Macdonald, I., Turner, L. J.: Serum fructose levels after sucrose or its constituent monosaccharides. Lancet $1968 \mathrm{I}$, 841-843

17. Lundquist, F., Wolthers, H.: The influence of fructose on the kinetics of alcohol elimination in man. Acta Pharmacol. Toxicol. (Kbh.) 14, 290-294 (1958)

18. Damgaard, S. E., Lundquist, F., Tønnesen, K., Hansen, F. V., Sestoft, L.: Metabolism of ethanol and fructose in the isolated perfused pig liver. Eur. J. Biochem. 33, 87-97 (1973)

19. Sestoft, L., Østergaard Kristensen, L.: Determination of unidirectional fluxes of phosphate across plasma membrane in isolated perfused rat liver. Am. J. Physiol. 236 (1979)

20. Woods, H. F., Eggleston, L. V., Krebs, H. A.: The cause of hepatic accumulation of fructose l-phosphate on fructose loading. Biochem. J. 119, 501-510 (1970)

21. Sestoft, L.: Regulatory processes in rat liver induced by sudden changes in fructose concentration. In: Regulation of hepatic metabolism. Alfred Benzon Symposium VI. Lundquist, F., Tygstrup, N. (Eds.), pp. 285-299. Copenhagen: Munksgaard 1974

22. Perheentupa, J., Raivio, K.: Fructose-induced hyperuricemia. Lancet 1967 II, 528-531

23. Raivio, K. O., Kekomäki, M. P., Mäenpää, P. H.: Depletion of liver adenine nucleotides induced by $D$-fructose. Biochem. Pharmacol. 18, 2615-2624 (1969)

24. Atwell, M, E., Waterhouse, C.: Glucose production from fructose. Diabetes 20, 193-199 (1971)

25. Corvilain, J., Tagnon, R.: Effects of fructose infusion on glucose uptake and circulating insulin-like activity in normal man. J. Physiol. (Lond.) 155, 337-342 (1961)

26. Cori, C. F.: The fate of sugar in the animal body. III. The rate of glycogen formation in the liver of normal and insulinized rats during the absorption of glucose, fructose and galactose. J. Biol. Chem. 70, 577-585 (1926)

27. Nilsson, L. H., Hultman, E.: Liver and muscle glycogen in man after glucose and fructose infusion. Scand. J. Clin. Lab. Invest. 33, 5-10 (1974)

28. Van den Berghe, G., Hue, L., Hers, H. G.: Effect of the administration of fructose on the glycogenolytic action of glucagon. Biochem. J. 134, 637-645 (1973)

29. Topping, D. L., Mayes, P. A.: The immediate effects of insulin and fructose on the metabolism of the perfused liver. Biochem. J. 126, 295-311 (1972)

30. MacDonald, J.: Effect on serum lipids of dietary sucrose and fructose. Acta Med. Scand. [Suppl.] 542, 215-219 (1972)

31. Bergstrøm, J., Hultman, E., Roch-Norlund, Aa. E.: Lactic acid accumulation in connection with fructose infusion. Acta Med. Scand. 184, 359-364 (1968)

32. Dietze, G., Wicklmayr, M., Mehnert, H.: Antiketogenic action of fructose in man. Diabetes 27, 709-714 (1978)

33. Cohen, A.M., Teitelbaum, A., Roseman, E.: Diabetes induced by a high fructose diet. Metabolism 26, 17-24 (1977)

34. Beck-Nielsen, H., Pedersen, O., Lindskov, H. O.: Impaired cellular insulin binding and insulin sensitivity induced by highfructose feeding in normal subjects. Am. J. Nutr. (in press)

Received: April 3, 1979

Dr. L. Sestoft

Hvidøre Hospital

Emiliekildevej 1

DK-2930 Klampenborg

Denmark 